\title{
The state of animal ethics
}

\author{
Reviewed by Emily Patterson-Kane, PhD
}

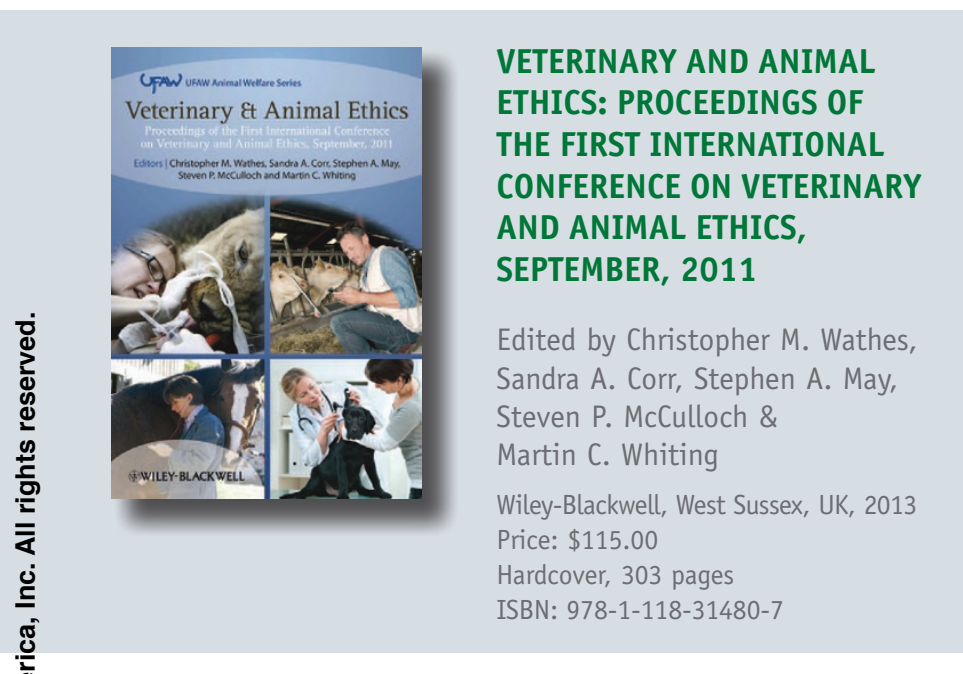

Veterinary and Animal Ethics documents the proceedings of the First International Conference on Veterinary and Animal Ethics, held in London, UK, in 2011. The major topics that were presented at the meeting are organized according to theme: the principles of veterinary and animal ethics, as well as the morality; ethical analyses; and cultural, political, legal and economic considerations of animal use.

John McInerny provides a rather good description of the meeting in the postscript to his chapter, the final one of the book: "There is a tendency for international conferences to be rather like multinational bombing raids. The various participants fly in from different directions at varying heights and speeds, drop their particular ordnance on what they believe is the target and then fly out again..." This book seems to essentially be a record of that process: the chapters vary greatly in scope, level (basic or advanced) and insight and do not seem to form a coherent whole. This is, perhaps, unsurprising, given that the book's subject is in a state of flux and development, but it means that the reader must actively strive to integrate the disparate information provided into a more general understanding of the current state of the discipline (arguably a state of confusion).

There are some areas where the text perhaps could have used a little more 'massaging' into a form suitable for a wider readership. As a minor example, Judy MacArthur Clark's introduction to 'Session II: Justifying Ends-The Morality of Animal Use' is written in the past tense, as if we have already heard the presentations, but is positioned in the book before the chapters to which it refers. Furthermore, the majority of the chapters specifically refer to animal use in the UK and, to some extent, in the rest of Europe, though informed readers could easily make parallels to other countries

Many of the individual chapters provide valuable explanations or summaries of topics where little published work is currently available. Veterinary and Animal Ethics makes it clear that many different concepts of what is 'good' for animals and people are projected onto human-animal interactions, including how we relate to pets, farmed animals, animals used for sport and wildlife. Consideration is given to a wide array of conceptual structures such as human medical ethics and principlism, the ethical matrix, telos and the human-animal bond, as well as to popular movements such as sustainable intensification versus radical naturalism, 'wicked problems,' animal 'enhancement' and futurism. Fragmented attempts are made to reconcile, harmonize or, in some cases, reject certain approaches, but the overall message is that the terrain is complicated and utilitarianism is currently king, at least when it comes to regulating animal use.

The contributors to this book raise several subjects that certainly deserve wider discussion. For example, I was particularly encouraged to see the question raised and addressed in the final panel discussion: does quantity of life, as well as quality, matter to an animal? In my opinion, this is a valid question that traditionally has been suppressed or excluded in animal science education, in which creating or ending life per se is often denied any moral consideration, positive or negative. This has led to practices such as large-scale culling of unwanted neonates (male layer chicks, for example) with which the public is increasingly uncomfortable.

Overall, I would recommend this book to anyone involved in animal-based activities who is already familiar with earlier landmark publications such as Animal Machines (Harrison, R.; 1964); The Report of the Technical Committee to Enquire into the Welfare of Animals kept under Intensive Livestock Husbandry Systems (Brambell, F.W.R.; 1965); and The Principles of Humane Experimental Technique (Russell, W.M.S. \& Burch, R.L.; 1959). Veterinary and Animal Ethics opens a window into the complexities of animal ethics. Its value lies in its broad scope, encompassing the different types of animal use and the ways in which the ethics of practicing veterinary medicine intersect with multiple facets of society, including economics, law, government and recreation. 